\title{
Topographic Specificity within Membranes of a Single Muscle Detected In Vitro
}

\author{
Srinivas Rao Chadaram, ${ }^{1,2}$ Michael B. Laskowski, ${ }^{1}$ and Roger D. Madison ${ }^{2,3,4}$ \\ ${ }^{1}$ WWAMI Medical Education Program and Department of Biological Sciences, University of Idaho, Moscow, Idaho 83843, Departments of ${ }^{2}$ Surgery and \\ ${ }^{3}$ Neurobiology, Duke University Medical Center, Durham, North Carolina 27710, and ${ }^{4}$ Research Service of the Veterans Affairs Medical Center, Durham \\ Veterans Affairs Medical Center, Durham, North Carolina 27705
}

Spinal motor pools project to target muscles forming distinct rostrocaudal topographic maps during development and regeneration. To define the mechanisms underlying these neuromuscular maps we studied the preferential outgrowth of embryonic spinal cord neurites on muscle membranes from different axial positions and explored the role of ephrin A ligands. We found all five ephrin As (EphAs) expressed in serratus anterior, gluteus maximus and diaphragm muscles. In the diaphragm, four of the five ephrin As are expressed as a caudal to rostral gradient. When ephrin A function is disrupted in muscle membranes by deletion of glycosyl-phosphatidylinositol anchored ephrin A ligands with phosphatidylinositol-specific phospholipase C enzyme treatment or by blocking of ephrin A ligands with EphA fusion proteins, or by genetic manipulation leading to ephrin A2/A5 mutant mice, the spinal cord neurites loose their preference for the membranes of corresponding axial position; suggesting a significant role for ephrins in topographic choices made by growing motor neurons. To closely approximate topographic choices presented to embryonic neurites in vivo, neurites within the phrenic motor pool were challenged to make outgrowth choices on membranes of their normal target, the diaphragm muscle. We observed that neurites from rostral cervical segments $\left(\mathrm{C}_{1}\right.$ and $\left.\mathrm{C}_{2}\right)$ prefer to grow on rostral diaphragm membranes; caudal cervical neurites $\left(\mathrm{C}_{6}-\mathrm{C}_{8}\right)$ choose caudal diaphragm membranes; a transition of positional preference occurs at $\mathrm{C}_{4}$ and this ability is lost in ephrin A2/A5 mutant mice. These results demonstrate for the first time topographical outgrowth of axons from within a motor pool onto a single target muscle in vitro.

Key words: diaphragm; neuromuscular; topography; muscle; ephrins; spinal cord; axon guidance

\section{Introduction}

A general pattern of neuromuscular innervation reveals that spinal motor pools form topographic maps onto the surface of their target muscles. Thus, rostral portions of a motor pool form synaptic contact with fibers in rostral portions of a muscle, whereas caudal motor neurons synapse caudally (Brown and Booth, 1983a,b; Bennett and Lavidis, 1984; Wigston and Sanes, 1985; Laskowski and Sanes, 1987; Laskowski and High, 1989). This ability of spinal neurites to distinguish axial origin of muscle regions is inherent to muscle because membranes of transgenic muscle cell lines induce similar growth preferences (Wang et al. 1999).

One candidate molecular system that plays a role in forming the topographic map is the ephrin A (EphA) tyrosine kinase system (Donoghue et al. 1996). Caudal spinal cord neurites, and to a lesser extent rostral neurites avoided growth on membranes expressing the ligand ephrin A5 (Wang et al. 2001). Moreover, in

\footnotetext{
Received July 5, 2007; revised Sept. 20, 2007; accepted 0ct. 12, 2007.

This work was supported by National Institutes of Health (NIH) Grant NS27024 and NIH Idea Network of Biomedical Research Excellence Grant P20RR016454 (M.B.L.). We thank Joshua Sanes for very helpful discussions throughout these studies. We also thank Ann Norton, Renata Lewis, and Judyta Misiurek for technical help in these studies. Roger D. Madison is a research career scientist for the Biological Laboratory Research and Development Service of the Department of Veterans Affairs.

Correspondence should be addressed to Dr. Michael B. Laskowski, WWAMI Medical Education Program, University of Idaho, P.0. Box 444207, Moscow, ID 83844-4207. E-mail: mlaskow@uidaho.edu.

D0I:10.1523/JNEUROSCI.3055-07.2007

Copyright $\odot 2007$ Society for Neuroscience $\quad 0270-6474 / 07 / 2713938-11 \$ 15.00 / 0$
}

vivo physiological studies revealed that overexpression of ephrin A5 or deletion of the genes for ephrin A2 and A5 degrade the neuromuscular map. Furthermore, ephrins A1 to A5 are endogenously expressed in embryonic muscles and in the diaphragm in particular (Feng et al. 2000). This endogenous expression diminishes in neonatal muscles and is undetectable in adults (Feng et al. 2000). The expression patterns of ephrin A ligands with age parallels the ability of growing neurites to detect positional differences in muscle membranes (Chadaram and Laskowski, 2003).

To define the mechanisms underlying positional neuromuscular maps, we have been studying growth patterns of neurites from embryonic spinal cord slices on lanes and carpets of membranes from muscles under a variety of conditions. We have shown previously that embryonic spinal cord neurites prefer to grow on membranes of muscles from a similar axial position (Wang et al., 1999). These data suggest but do not prove that the ability of axons to distinguish ephrins on muscle membranes may help explain their ability to innervate selectively muscles or portions of muscles in vivo. Although ephrin levels differ among muscles, it is not clear whether they differ within single muscles, and although rostral and caudal spinal cord neurites distinguish between muscles, it is not clear whether they distinguish differences within a single muscle, particularly in their normal target muscle. Finally, in vivo, it is not clear whether defects in axonal projections by ephrin mutants reported by Feng et al. (2000), reflected a need for ephrins in the target muscle or the innervating nerve. 
Table 1. PCR oligo primers and sequence specific hybridization FRET probes for ephrin As and housekeeping gene HPRT designed and synthesized by Proligo

\begin{tabular}{|c|c|c|c|c|c|}
\hline & Oligo name & GenBank id & Sequence: $\left(5^{\prime}-3^{\prime}\right)$ & Size & Position \\
\hline 1 & ephrinA1_forward & gi 12805174 gb BC002046.1 & 5'-TCATgCggTTggACAC-3' & 16 & $994-1009$ \\
\hline 2 & ephrinA1_reverse & gi 12805174 gb BC002046.1 & 5'-CCgggCTACAAACCTC-3' & 16 & $1172-1187$ \\
\hline 3 & ephrinA1_probeA & gi 12805174 gb BC002046.1 & 5'-AgCCAggTACAgAAgAggC(Fluo)-3' & 19 & $1100-1118$ \\
\hline 4 & ephrinA1_probeB & gi 12805174 gb BC002046.1 & 5'-(Red640)CTTgggCTgACCCAgCA(Phosphate)-3' & 17 & $1121-1137$ \\
\hline 5 & ephrinA2_forward & gi 29145116 gb BC048697.1 & 5'-AggTTTATgTgCgTCCA-3' & 17 & $509-525$ \\
\hline 6 & ephrinA2_reverse & gi 29145116 gb BC048697.1 & 5'-gTCAgAgggCAAAggT-3' & 16 & $691-706$ \\
\hline 7 & ephrinA2_probeA & gi 29145116 gb BC048697.1 & 5'-CACCgTCCCTgTgCTgT(Fluo)-3' & 17 & $615-631$ \\
\hline 8 & ephrinA2_probeB & gi 29145116 gb BC048697.1 & 5'-(Red640)TCCCTTCTgggCTCCTAgT(Phosphate)-3' & 19 & $634-652$ \\
\hline 9 & ephrinA3_forward & gi 12861020 dbj AK020438.1 & 5'-gATTgAATCCAAgTTTACAAATAgAC-3' & 26 & $633-658$ \\
\hline 10 & ephrinA3_reverse & gi 12861020 dbj AK020438.1 & 5'-TgTgCgTTgCATAggT-3' & 16 & $885-900$ \\
\hline 11 & ephrinA3_probeA & gi 12861020 dbj AK020438.1 & 5'-ACAggCAgAgTCCCTTCC(Fluo)-3' & 18 & $751-768$ \\
\hline 12 & ephrinA3_probeB & gi 12861020 dbj AK020438.1 & 5' -(Red640)TTCTTAACCTTgACCTTTCTCgACTTCC(Phosphate)-3' & 28 & $771-798$ \\
\hline 13 & ephrinA4_forward & gi $12848791 \mathrm{dbj}$ AK012195.1 & 5'-gAgAAAgCggTACgTCC-3' gi 12848791 dbj AK012195.1 & 17 & $600-616$ \\
\hline 14 & ephrinA4_reverse & gi 12848791 dbj AK012195.1 & 5'-ggCATCgCCTgTATgg-3' & 16 & 779-794 \\
\hline 15 & ephrinA4_probeA & gi 12848791 dbj AK012195.1 & 5'-CTgCTCCCAATCCTCCgT(Fluo)-3' & 18 & $668-685$ \\
\hline 16 & ephrinA4_probeB & gi 12848791 dbj AK012195.1 & 5'-(Red640)CCTgAgAgTTCTgTgAgCCA(Phosphate)-3' & 20 & $688-707$ \\
\hline 17 & ephrinA5_forward & gi 25955544 gb BC040218.1 & 5'-ATAgCTTTggCTACTCCT-3' & 18 & $1853-1870$ \\
\hline 18 & ephrinA5_reverse & gi 25955544 gb BC040218.1 & 5'-CTgACTCTCCTggTgAT-3' & 17 & $2030-2046$ \\
\hline 19 & ephrinA5_probeA & gi 25955544 gb BC040218.1 & 5'-gTggCCTTTCCCCAATTCCC(Fluo)-3' & 20 & 1948-1967 \\
\hline 20 & ephrinA5_probeB & gi 25955544 gb BC040218.1 & 5'-(Red640)CCCgATACCCACgTTCTgC(Phosphate)-3' & 19 & $1970-1988$ \\
\hline 21 & RatHPRT_forward & gi 70778838 ref NM_012583.2 & 5'-CCAgCgTCgTgATTAgT-3' & 17 & $83-99$ \\
\hline 22 & RatHPRT_reverse & gi 70778838 ref NM_012583.2 & $5^{\prime}-A C A C A g A g g g C C A C A A-3^{\prime}$ & 16 & $251-266$ \\
\hline 23 & RatHPRT_probeA & gi 70778838 ref NM_012583.2 & 5'-ATTTggAAAAggTgTTTATTCCTCATggAC(Fluo)-3' & 30 & $158-187$ \\
\hline 24 & RatHPRT_probeB & gi 70778838 ref NM_012583.2 & 5'-(Red640)ATTATggACAggACTgAAAgACTTgC(Phosphate)-3' & 26 & $190-215$ \\
\hline
\end{tabular}

We have now performed experiments to address these issues. First, using reverse transcription (RT)-PCR we show differences in endogenous expression of ephrin A ligands in two different muscles and also within a single muscle. Second, using our previously described culture system, we show that differences in neurite selectivity between muscles are ephrin dependent. Third, we show that axons can distinguish differences within a single muscle, and that this distinction is ephrin dependent. Together, these data answer some of the questions above, and provide a cellular mechanism for the physiological data obtained in vivo.

\section{Materials and Methods}

Measurement of endogenous expression of ephrin As

Tissue harvest. Postnatal day 0 ( $\mathrm{P} 0)$ to $\mathrm{P} 3$ mouse pups were decapitated and placed in RNAlater solution (Ambion, Austin, TX; $n=9$ separate litters). The diaphragm muscle was isolated, freed from surrounding tissues and pinned flat while still immersed in RNAlater. Each diaphragm was divided into left and right halves, and each half was further divided into four rostral to caudal sectors of approximately equal size. Corresponding sectors from all pups in a litter were placed in a single vial with RNAlater and coded. The vials containing muscle tissue were maintained at $4^{\circ} \mathrm{C}$ overnight, and then placed at minus $20^{\circ} \mathrm{C}$ for long-term storage and shipping. The nine litters were randomly grouped into five batches of approximately equal muscle volume for total RNA harvest and subsequent quantitative two-step RT-PCR. The tissue code identifying diaphragm sector location was not broken until all quantitative (Q)-PCR analyses were completed and data had been analyzed.

RNA isolation and reverse transcription. All reactions were performed using RNase-free conditions and highly purified water (Barnstead, Dubuque, IA). Total RNA was isolated using the MasterPure RNA Purification Kit (Epicenter, Madison, WI). Possible contaminating DNA was removed via a DNase treatment step following the manufacturer's suggested protocol. The purified RNA was resuspended in RNASecure (Ambion) and stored at $-80^{\circ} \mathrm{C}$ in RNase-free siliconized microcentrifuge tubes until used for reverse transcription. The integrity and concentration of the purified RNA was assessed with an Agilent (Waldbronn, Germany) Bioanalyzer 2100 using RNA 6000 NanoChips. Only RNA samples that demonstrated distinct $18 \mathrm{~S}$ and $28 \mathrm{~S}$ ribosomal bands were used for subsequent steps. RT of the RNA to cDNA was performed using random hexamers as primers and the Advantage RT-for-PCR Kit (BD Biosciences, Palo Alto, CA). All RT reactions used $10 \mu \mathrm{g}$ of total RNA as the starting material in a $50 \mu \mathrm{l}$ reaction. After incubation at $42^{\circ} \mathrm{C}$ for $1 \mathrm{~h}$, samples were heated at $94^{\circ} \mathrm{C}$ for $5 \mathrm{~min}$ and then diluted to $100 \mu \mathrm{l}$ with water and stored at $-80^{\circ} \mathrm{C}$ until used for the Q-PCR.

Ephrin A standard curves and quantitative PCR. PCR primers and sequence specific hybridization probes for fluorescence resonance energy transfer (FRET) for each of the five ephrin As and the housekeeping gene hypoxanthine phosphoribosyltransferase (HPRT) were designed and synthesized by Proligo (Proligo Primers and Probes, Boulder, CO) from the mouse mRNA sequences to generate PCR products of $\sim 200$ base pairs (Table 1). To most reliably relate a target mRNA to a housekeeping gene it is important that both are expressed at comparable levels. Several candidate housekeeping genes including 18sRNA, $\beta 2$-microglobulin, glucose-6-phosphate dehydrogenase, 5-aminolevulinate synthase, and porphobilinogen deaminase were tested, and HPRT was chosen because it is a constitutively expressed house keeping gene with levels as low at 1-10 molecules per cell, which makes it suitable as an endogenous mRNA control in RT-PCR for high sensitive quantification of low copy mRNAs. HPRT was selected as the housekeeping gene because its expression levels were in the same range as the ephrins. All FRET hybridization probes were purified by Reverse phase HPLC. The resulting observed fluorescence signal in the real-time Q-PCR instrument (LightCycler; Roche, Indianapolis, IN) comes from the internal FRET probes, and is highly specific for the target sequence regardless of nonspecific PCR products that may be amplified during the reaction.

Embryonic mouse brain and P0 diaphragm were used as sample tissues to test and optimize all of the PCR primers, probes, and cycling programs. PCR products from these test runs were purified (QIAquick PCR purification kit 250; Qiagen, Valencia, CA) and analyzed with an Agilent Bioanalyzer 2100 using the DNA 500 LabChip Kit. PCR parameters (primer/probe concentrations, cycle variables, etc.) were optimized to yield selectively the correct sized product while minimizing contaminating primer dimers and nonspecific products. PCR products for each target were then generated in larger quantities, purified, and the purity and concentration determined by the Agilent Bioanalyzer. Concentrations of each stock PCR product were translated to number of copies per $\mathrm{ml}$, and known numbers of copies of each target were then used as external standards for each ephrin and the HPRT housekeeping gene. Six 
point standard curves were run for each ephrin A that covered approximately two and a half orders of magnitude; routine sensitivity of detection was 100 copies or less. The number of copies of each target mRNA within each experimental sample was then calculated using the appropriate respective standard curve. We then normalized the expressed copy number by the amount of HPRT expression in each sample (i.e., standardizing the ephrin A copies to a set amount of HPRT). Results are averages from six independent RNA isolations for each tissue sample, run in duplicate for each PCR.

Q-PCR was performed using master mixes for all reactions consisting of $3 \mathrm{mM} \mathrm{MgCl}_{2}, 0.5 \mu \mathrm{m}$ forward and reverse primer, and $0.2 \mu \mathrm{m}$ of both hybridization probes. Two microliters of DNA template was used in a 20 $\mu \mathrm{l}$ reaction mix for DNA amplification and data collection using the LightCycler System (Roche). Final cycling parameters included a hotstart preincubation step of $10 \mathrm{~min}$ at $95^{\circ} \mathrm{C}$ followed by 45 cycles of $10 \mathrm{~s}$ at $95^{\circ} \mathrm{C}, 10 \mathrm{~s}$ at $52-55^{\circ} \mathrm{C}$ (based on Tm of primers and probes), $8-12 \mathrm{~s}$ at $72^{\circ} \mathrm{C}$ (based on product size, i.e., $\sim 25 \mathrm{bp} / \mathrm{s}$ ), and the temperature ramp was always $20^{\circ} \mathrm{C} / \mathrm{s}$. Fluorescence was measured at the end of each annealing phase. The raw data were analyzed with LightCycler software version 3.5. The ratio of signals measured in channel 2/channel 1 was used to calculate the crossing point $(\mathrm{CP})$ values. All samples were run multiple times, at least in duplicate. A negative control $\left(\mathrm{H}_{2} \mathrm{O}\right.$ instead of cDNA) was included to check for cross contamination in every run; these controls were always negative.

\section{P0 muscle membrane preparation}

The procedure for the preparation of muscle membranes is similar to that of Walter et al., (1987). All procedures were performed in accordance with University of Idaho Animal Care and Use Committee Guidelines. Neonatal pups born to timed-pregnant female wild-type and ephrin $\mathrm{A} 2-/$ - ephrin $\mathrm{A} 5-/$ - double mutant mice were used for this study. $\mathrm{P} 0$ is the day the pups were born. Within $24 \mathrm{~h}$ of their birth, the pups were anesthetized by putting them on ice until all movement ceased, usually 10 $\mathrm{min}$. Then the pups were decapitated and placed in dissecting medium for muscle removal (2.0 M NaCl, $1.0 \mathrm{M} \mathrm{KCl}, 1.0 \mathrm{M} \mathrm{MgCl}_{2}, 0.5 \mathrm{M} \mathrm{CaCl}_{2}, 0.3$ м HEPES, $0.011 \mathrm{mg} / \mathrm{ml}$ glucose, $0.3 \mathrm{mg} / \mathrm{ml}$ penicillin, and $0.1 \mathrm{mg} / \mathrm{ml}$ streptomycin in deionized water, $\mathrm{pH}$ 7.2-7.3) (Wang et al., 1999). The serratus anterior, gluteus maximus and diaphragm muscles were removed. The diaphragm muscle was cut into right and left halves. (see Fig. 1) Each half was further divided into rostral (sectors 1-4) and caudal (sectors 5-8). The muscle pieces were immediately frozen in liquid nitrogen and stored at $-80^{\circ} \mathrm{C}$ as "rostral" and "caudal" muscle tissue.

The frozen muscle masses were thawed and thoroughly minced in 2-5 volumes of homogenization buffer $\left(10 \mathrm{~mm}\right.$ Tris- $\mathrm{HCl}, 1.5 \mathrm{~mm} \mathrm{CaCl}_{2}, 1$ mM Spermidine, $50 \mu \mathrm{M}$ Leupeptin, $1 \mu \mathrm{M}$ Aprotinin, $2 \mu \mathrm{M}$ Pepstatin A, $\mathrm{pH}$ 7.4) with the help of a Polytron Tissue-mizzer. The muscles were homogenized with the Polytron at $70 \%$ maximal speed for $3 \times 30$ s. The homogenate was centrifuged in a Sorvall (Global Medical Instrumentation, Ramsey, MN) Ultracentrifuge at $12,000 \times g(70.1$ Ti rotor $)$ at $11,000 \mathrm{rpm}$ for $20 \mathrm{~min}$ at $4^{\circ} \mathrm{C}$. The supernatant was separated out and kept aside on an ice bath while the sediment was homogenized and centrifuged at the same speed. The supernatant was collected again and mixed with the previous supernatant and the sediment was discarded. The supernatant was then subjected to a $5-50 \%$ sucrose step gradient by slowly injecting $0.5 \mathrm{ml}$ of $5 \%$ sucrose at the bottom of the homogenate, followed by $1.5 \mathrm{ml}$ of $50 \%$ sucrose below it. Then it was centrifuged at 50,000 $\times g(70.1 \mathrm{Ti}$ rotor) at 30,000 rpm for $10 \mathrm{~min}$ at $4^{\circ} \mathrm{C}$. The muscle cell membranes were collected from the interface between $5 \%$ and $50 \%$ sucrose. Membranes were washed with PBS+ $\left(136 \mathrm{~mm} \mathrm{NaCl}, 2.6 \mathrm{~mm} \mathrm{KCl}, 8.1 \mathrm{~mm} \mathrm{Na}_{2} \mathrm{HPO}_{4}\right.$, $1.4 \mathrm{mM} \mathrm{NaH}_{2} \mathrm{PO}_{4}, 0.68 \mathrm{mM} \mathrm{CaCl}_{2}, 0.4 \mathrm{~mm} \mathrm{MgCl}_{2}, 0.3 \mathrm{mg} / \mathrm{ml}$ penicillin, $0.1 \mathrm{mg} / \mathrm{ml}$ streptomycin, $50 \mu \mathrm{M}$ leupeptin, $1 \mu \mathrm{M}$ aprotinin, and $2 \mu \mathrm{M}$ pepstatin $\mathrm{A}, \mathrm{pH} 7.40)$ once at $200 \mathrm{k} \times g$ (70.1 Ti rotor) at 47,000 $\mathrm{rpm}$ for $30 \mathrm{~min}$ at $4^{\circ} \mathrm{C}$. The supernatant was discarded and the membrane pellets were resuspended in $1 \mathrm{ml}$ of PBS + using a syringe. The membrane solution was divided into several small sterile tubes and stored at $-80^{\circ} \mathrm{C}$. Total protein concentration was determined by using the Bio-Rad (Hercules, CA; Bradford) protein assay (Bradford, 1976; Simpson and Sonne, 1982).

\section{Lane preparation with $\mathrm{P} 0$ muscle membranes}

Nucleopore filters coated with $20 \mu \mathrm{g} / \mathrm{ml}$ laminin, as well as noncoated filters, were used for membrane deposition. Rostral and caudal sector membrane fragments were adjusted to the same protein concentration of $400 \mu \mathrm{g} / \mathrm{ml}$ with PBS. Fluorescein or rhodamine labeled micro beads $(0.5$ $\mu \mathrm{g} / \mathrm{ml}$ ) were mixed with the membrane fragment solution. The Walters method of preparing lanes was used (Walter et al., 1987). The membrane mixture solution was layered onto the Nucleopore filter, which was on a silicone matrix grid, consisting of $90 \mu \mathrm{m}$ alternating lanes. Approximately $100 \mu \mathrm{l}$ of the rostral or caudal sector membrane suspension was aspirated through the filter by use of a vacuum unit, forming alternating $90 \mu \mathrm{m}$ "first lanes" or "lane A." The filter was transferred onto a porous frit to layer the "second lanes" or "lane B." The second lanes, formed from either rostral or caudal sector membranes, were made by plugging the unoccupied lanes with membranes. After layering the filter with alternate rostral and caudal lanes, it was immediately put into PBS and then transferred into culture medium for coculture. For single lane neurite outgrowth assays only one lane (i.e., first lane/lane A) was deposited on the nucleopore filters as described above.

\section{E15 spinal cord slice preparation and coculturing}

Timed-pregnant female rats of the Sprague Dawley strain were used for the isolation of spinal cord slices. Preliminary studies showed similar growth preferences of these neurites on neonatal rat or mouse muscle membranes. Embryonic day 15 (E15) is $15 \mathrm{~d}$ after the copulatory plug has been formed. On the 15th gestational day, the mother was anesthetized and the embryos were removed and decapitated. The vertebral column was carefully removed with the meninges and the spinal cord intact (Fig. 1). Approximately 4 - to 6-mm-long pieces of the vertebral column with the intact spinal cord were cut from cervical (C1) to upper thoracic (T1, T2) region for the "rostral spinal explants." Dorsal and ventral roots were used for orientation. In practice, slices were taken from upper to middle cervical cord C1-C4 and occasionally C5 for explantation. Similarly for "caudal spinal explants" the vertebral column with intact spinal cord was cut from the upper lumbar region (L1-L2) to the upper-sacral region (S1-S2). This region represents the lumbar enlargement. These pieces were then placed into $4 \%$ liquid agar at $40^{\circ} \mathrm{C}$ and allowed to settle while cooling on an ice bath. When the agar solidified completely, small cubes of agar with the vertebral column pieces embedded in them were cut and mounted for sectioning on a Vibratome. Sections of $300 \mu \mathrm{m}$ thickness were cut in chilled dissecting medium. The spinal cord slices were dissected out of these sections very carefully without the meninges. Each slice was bisected into dorsal and ventral pieces using the central canal as an anatomical landmark, and only the ventral piece was used. These ventral spinal cord slices were then ready for deposition onto the membrane-coated nucleopore filters.

Spinal cord slices on membrane-coated filters were cultured in six well dishes (Costar-3506; Corning, Corning, NY). After deposition of the spinal cord slices, the dishes were put in the incubator with settings at $37^{\circ} \mathrm{C}, 5 \%(100 \mathrm{ml} / \mathrm{min}) \mathrm{CO}_{2}$ and $2 \mathrm{l} / \mathrm{min}$ air. After $10-15 \mathrm{~min}$ of incubation, which helps the spinal cord slices to adhere well to the filters, 2-3 $\mathrm{ml}$ of culture medium made according to Xie and Ziskind-Conhaim (1995) were added to each well. Each $100 \mathrm{ml}$ of culturing medium contained $50 \mathrm{ml}$ of DMEM, $25 \mathrm{ml}$ of HBSS, $15 \mathrm{ml}$ of double distilled water, $2.3 \mathrm{ml}$ of $20 \%$ glucose, $1.6 \mathrm{ml}$ of $23.8 \%$ HEPES, pH 7.2 , and $8 \mathrm{ml}$ of heat-inactivated fetal bovine serum. The cocultures were incubated for $3 \mathrm{~d}$.

In a second set of experiments, we isolated the entire cervical region of the spinal cord (Fig. 1). After embedding the block of cord in agar as described above, cervical segments $\mathrm{C}_{1}$ and $\mathrm{C}_{2}$ or $\mathrm{C}_{6}, \mathrm{C}_{7}$, and $\mathrm{C}_{8}$ were identified and sliced on the Vibratome, using their dorsal roots as boundaries. Then the outgrowth patterns of $\mathrm{C}_{1}-\mathrm{C}_{2}$ (rostral cervical) versus $\mathrm{C}_{6}-\mathrm{C}_{8}$ (caudal cervical) on diaphragm membranes were compared.

In a third series of experiments, the cervical region of the spinal cord was removed, placed in agar and each segment $\left(C_{1}\right.$ through $\left.C_{8}\right)$ was isolated and kept separate for coculturing. The goal of this series was to determine whether a progressive pattern of selectivity could be detected along the rostrocaudal extent of the cervical spinal cord. 


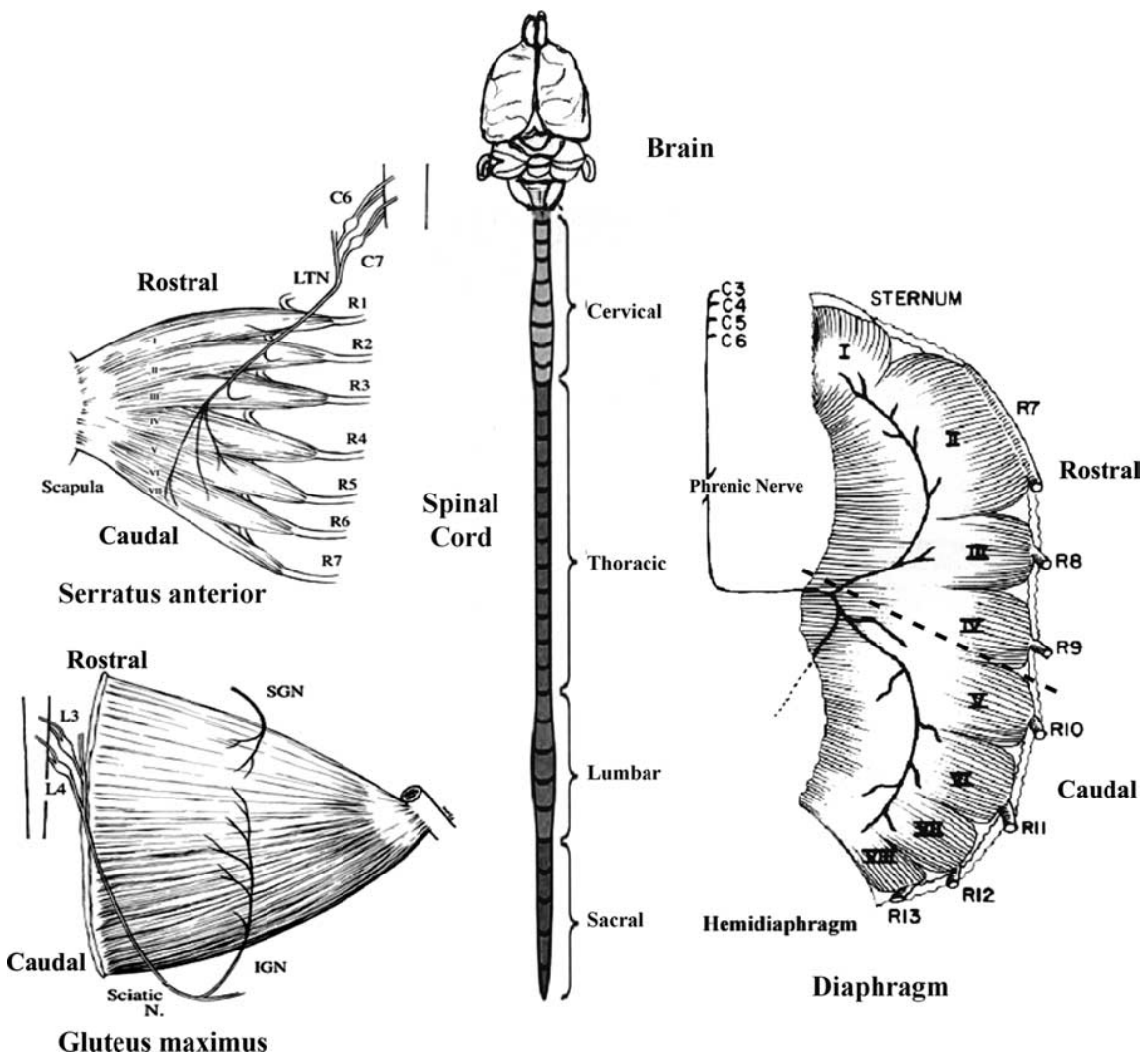

Figure 1. Sketches of serratus anterior muscle, gluteus maximus, spinal cord, and diaphragm muscles of the mouse or rat. The serratus anterior muscle is innervated by cervical spinal roots $\mathrm{C} 6$ and $\mathrm{C} 7$ through the long thoracic nerve (LTN) and is divided into seven sectors arising from ribs $\mathrm{R} 1-\mathrm{R} 7$. The muscle is oriented in a rostrocaudal direction. The rodent spinal cord is illustrated and consists of 8 cervical, 13 thoracic, 5 lumbar, and 5 sacral segments. For coculture experiments, the cervical or lumbar regions were isolated and sliced transversely. In some experiments, all eight cervical segments were isolated individually for cocultures. The gluteus maximus muscle, also oriented rostrocaudally is innervated by spinal lumbar roots L3 and L4. Although the gluteus receives input from both the inferior gluteal nerve (IGN) and superior gluteal nerve (SGN), its primary innervation is from the IGN. The right hemidiaphragm is illustrated together with its innervation by the phrenic nerve arising from cervical roots $\mathrm{C} 4$ - $\mathrm{C} 7$ (and occasionally (3). The muscle is divided into eight sectors labeled I-VIII. The sectors are attached to the sternum and ribs $7-13$. It is divided into two sub regions rostral (sectors I-IV) and caudal (sectors V-VIII) for the stripe assay.

Staining of neurites and scoring of growth preferences

After $4 \mathrm{~d}$ of incubation, the cocultures were first observed under a Nikon (Tokyo, Japan) TMD inverted microscope with fluorescein and rhodamine optics, as well as under transmitted light. Preliminary data were recorded at this point, and all the cocultures that showed significant growth (a minimum of five neurites growing out on muscle lanes) were selected for staining. Outgrowth preferences in each case were graded as either selective or random. Selective growth was that in which neurites or axons grew into four or more lanes of a single type. Additional stringency required minimal crossing over into adjacent lanes. These strict criteria were established to demonstrate a strong bias for a specific lane. All other cultures were scored as "random," wherein the neurites grew across lanes without any noticeable bias for either set of lanes. Included in the category "random" were truly nonselective growth where neurites crossed lane boundaries and showed no lane preference. Also included in the random category were cocultures exhibiting restrictive growth on both lanes A and B or a variety of patterns that did not fit our strict criteria of "selective" growth as described above. Pictures of the cocultures were also taken at this point. The cocultures were stained by the neurofilament immunocytochemistry method using either the fluorescein-labeled secondary anti-rabbit IgG or the biotinylated HRP anti-rabbit IgG against the primary anti-neurofilament antibody, which is the IgG fraction of rabbit antiserum (Donoghue et al., 1996; Wang et al., 1999). The stained cocultures were observed under a Bio-Rad MRC 1000 argon/krypton laser confocal microscope using fluorescein and rhodamine optics as well as under transmitted light. The final observations were recorded at this point, and only cases that met the following criteria were scored: lanes were distinct, axons were stained adequately, and outgrowth was adequate to judge growth preferences (Nakamoto et al., 1996). The grader and experimenter were blind to the identity of membranes at the time of taking observations. A neutral person who noted the type of beads added to the membrane suspension did the blinding. Membrane identity was revealed only after all the observations had been taken and the data were pooled based on the microbead labels.

Technical limitations of selective outgrowth Unfortunately, the lack of specific markers of embryonic mammalian motor neurons prevents directly proving the source of the neurites in such experiments, hence our use of the term "spinal neurites" rather than "spinal motor neurites." That being said, we have taken several steps to maximize the likelihood that a "large percentage" of such neurites are from motor neurons. Our methods of spinal cord isolation, vibratome slicing of explants, and culture conditions are identical to those initially described by Xie and Ziskind-Conhaim (1995). In that pioneering work the authors performed retrograde labeling of the outgrowing neurites with DiI and demonstrated exclusive labeling of clusters of neurons in the lateral and medial ventral horn in $\sim 97 \%$ of explant cultures. The general morphology and location of the labeled neurons were similar to those for spinal motor neurons at this stage of development in vivo, as were many of the physiological properties. In addition, we have previously shown that virtually all of the outgrowing neurites in such cultures stain with acetylcholine transferase (Fig. $1 F$ ) (Wang et al., 1999). We have further increased the likely percentage of motor neurons in our spinal cord explants by using only the ventral halves of the spinal cord slices.

\section{Phospholipase C enzyme treatment of membranes}

To verify whether the guidance molecule was a glycosyl-phosphatidylinositol (GPI) anchored protein, membranes were incubated with phosphatidylinositol-specific phospholipase C (PI-PLC $0.1 \mathrm{U} / \mathrm{mg}$ ) for 45 min at $37^{\circ} \mathrm{C}$, which specifically cleaves GPI-anchored proteins from the membrane surface (Drescher et al., 1995). After centrifugation at $980 \mathrm{~K}$ rpm for 15 min in a Beckman (Beckman Coulter, Fullerton, CA) TLA 100.3 ultracentrifuge, the PI-PLC-released proteins were found in the supernatant (Drescher et al., 1995). The pelleted membranes were used in the in vitro stripe assay. If the membranes lost their guidance ability after treatment, it would suggest that the guidance molecule is a GPIanchored protein.

\section{Receptor bodies and fusion proteins (EphA5-Fc) to test the} presence of ephrin A ligands in muscle membranes

The Eph receptors expressed on the growing axons bind to their respective ephrin ligands, which are expressed on the membranes of the target cells or the guiding cells (Kilpatrick et al., 1996; Ohta et al., 1997; Yue et al., 1999, Iwamasa et al., 1999) (for review, see Wilkinson 2001; Knoll and Drescher, 2002; Eberhart et al., 2004). This interaction helps the axons to recognize their targets, which is also crucial in their elongation and propagation to the targets. To test the impact of blocking these ligands on differential outgrowth, we used receptor bodies or fusion proteins. Receptor bodies are genetically engineered recombinant receptors produced in baculoviruses, and fusion proteins are receptors expressed from COS cell lines and isolated with the help of the Fc tags.

EphA fusion bodies were added in solution to the muscle membrane 
stripes at the same time as the explants were placed in culture. The fusion bodies attach to the ephrin ligands on the membrane stripes, and thus inhibit the ability of the Eph receptors on the subsequently growing neurites ( $\sim 24 \mathrm{~h}$ later) from interacting with the already occupied ephrin ligands on the membrane stripes. Blocking of the ephrin ligands leads to a loss in the guiding ability of the membranes as a result of competitive inhibition (for review, see Huber et al., 2003; Flanagan, 2006).

To test the effect of competitive inhibition in our culture system, EHK-1 receptor bodies (analogues of Eph A receptors) $(10 \mu \mathrm{g} / \mathrm{ml})(\mathrm{Re}-$ generon Pharmaceuticals, Tarrytown, NY) or EphA5-Fc receptor fusion proteins $(10 \mu \mathrm{g} / \mathrm{ml})$, were added to the medium used for the coculture. Likewise, $\mathrm{hFc}$ fragments (human immunoglobin $\mathrm{Fc}$ ) were added to the culture medium to serve as a mock control, and cocultures without any additions to the culture media served as additional controls. In the stripe assay, if the receptor bodies caused a loss of selectivity, changed the pattern of growth or changed the level of fasciculation of the growing neurites, it would indicate the existence of the ephrin A ligands on the muscle membranes.

The EphA5-Fc fusion proteins used in the study were produced by transfecting COS-7 cells with the EphA5-Fc expression plasmid (a gift from Nicholas W. Gale, Regeneron Pharmaceuticals). COS-7 cells were plated at 1 million cells per $10 \mathrm{~cm}$ dish in COS media (DMEM, 10\%FCS, $1 \times$ L-glutamine, and $1 \times$ penicillin/streptomycin) and cultured overnight at $37^{\circ} \mathrm{C}$ and $5 \% \mathrm{CO}_{2}$. Approximately $24 \mathrm{~h}$ after plating, the cells were transfected with Lipofectamine Reagent (Invitrogen, Gaithersburg, $\mathrm{MD}$ ) according to the manufacturer's protocol using $8 \mu \mathrm{g}$ of DNA/10 cm plate. The next day, the cells were fed with serum-free COS media and $48 \mathrm{~h}$ after feeding the media was collected. The EphA5-Fc protein was purified by binding to protein G sepharose 4 fast flow (GE Healthcare, Piscataway, NJ) and eluting with $100 \mathrm{~mm}$ glycine, pH 2.4 into $1 \mathrm{~m}$ TrisCL, pH 8.0 (to neutralize the glycine). Fractions were assayed for protein concentration by Bradford assay (Bradford, 1976) and appropriate fractions were pooled and dialyzed to PBS. The dialyzed protein was then concentrated using Centricon concentrators (Amicon, Beverly, MA).

\section{Statistical analysis}

Data were analyzed by SAS Software (SAS Institute, Cary, NC), comparing growth proportions (counts) between the two types (rostral vs caudal) of spinal cord neurites on different substrates, using $\chi^{2}$ tests. The $\chi^{2}$ test was used to compare actual counts (cultures) versus expected counts. The null hypothesis was that selective growth of rostral neurites was no different from that of caudal neurites. If the growth pattern of the two types of neurites differed, the null hypothesis was rejected. This test is exactly equivalent to a $Z$ test of proportions. Fisher's test was used for differences in neurite outgrowth in single lane assays.

\section{Statistical analysis for $Q-P C R$}

The normalized number of copies of each of the ephrins was quantified as described above. The copy number of the five ephrin As within each of the four diaphragm sectors was compared by ANOVA, followed by direct $t$ tests (Student-Neuman-Keuls) where appropriate.

\section{Results \\ Endogenous expression of ephrin As differs in serratus versus gluteus muscles}

If ephrin As play a role in forming neuromuscular topography, one would expect a difference in expression of ephrins in a muscle located rostrally and one located caudally. Two muscles that display topographic maps and are innervated by motor pools at extreme ends of the neuraxis are the serratus anterior and the gluteus maximus. Table 2 summarizes the results of quantitative RT-PCR measurements of the five ephrin As in mouse serratus and gluteus muscles. Ephrins A2, A4, and A5 are significantly higher in the rostral serratus muscle than the caudal gluteus. No significant differences in ephrins A1 or A3 were observed.
Table 2. Endogenous expression of ephrin As in serratus and gluteus whole muscles

\begin{tabular}{|c|c|c|}
\hline & $\begin{array}{l}\text { Serratus anterior } \\
\text { rostral }\end{array}$ & $\begin{array}{l}\text { Gluteus } \\
\text { caudal }\end{array}$ \\
\hline \multicolumn{3}{|l|}{ Ephrin A } \\
\hline A1 & $18.8 \pm 2.0$ & $15.3 \pm 1.9$ \\
\hline$A 2^{*}$ & $9.0 \pm 1.3$ & $5.3 \pm 0.6$ \\
\hline A3 & $1.3 \pm 0.7$ & $0.4 \pm 0.09$ \\
\hline$A 4^{* *}$ & $4.1 \pm 0.3$ & $2.6 \pm 0.3$ \\
\hline$A 5^{* *}$ & $11.7 \pm 1.0$ & $7.7 \pm 0.5$ \\
\hline
\end{tabular}

${ }^{*} p<0.05 ; *{ }^{*} p<0.01$.

\section{Selective outgrowth of embryonic spinal neurites is ephrin A dependent}

Although we have previously demonstrated neuromuscular topography in both the serratus and gluteus muscles, we have not previously demonstrated whether this map is ephrin dependent. To test this dependence we developed three independent assay methods. First, we measured selective outgrowth of spinal neurites on muscle membranes prepared from control mice to membranes prepared from ephrin A2-/- ephrin A5-/- double mutant mice. Second, we measured selective growth on muscle membranes with or without pretreatment with PI-PLC. Third, we measured selective outgrowth on membranes in the presence or absence of Eph fusion protein receptor bodies.

In the first series of experiments cervical (rostral) or lumbar (caudal) E15 spinal cord slices were cocultured on alternating stripes of $\mathrm{P} 0$ serratus (rostral) and gluteus (caudal) muscle membranes. Figure 2, $A$ and $B$, illustrate that rostral neurites grow preferentially on serratus (rostral) muscle membranes, whereas caudal neurites grew preferentially on gluteus (caudal) membranes. Figure $2 C$ summarizes the results of 119 rostral and 122 caudal cocultures. This difference in preferential outgrowth is abolished in muscle membranes isolated from ephrin A2 - /ephrin A5-/- double mutant mice (Fig. 3A,B). Spinal cord neurites are less selective in outgrowth on membranes from serratus or gluteus membranes from the mutant mouse membranes. Figure $3 C$ summarizes the results from 96 cocultures of rostral spinal cord slices and 108 cocultures of caudal spinal cord slices. No differences in growth preferences were observed by spinal neurites on muscle membranes from ephrin A2-A5 mutant mice.

In a second series of experiments, we measured the effect of PI-PLC on selective neurite outgrowth. The PI-PLC enzyme specifically cleaves GPI-anchored proteins from the membrane surface. Ephrin A ligands are GPI anchored, and hence they would be deleted post PI-PLC treatment (Drescher et al., 1995). Figure 4 summarizes the results of 545 cocultures. In $A$, on membranes pretreated with control buffer, rostral and caudal spinal cord neurites exhibit positional preference by preferring to grow on muscle membranes from corresponding axial position $(p<$ 0.001 ). However, in Figure $4 B$, the positional preference is lost in both caudal and rostral spinal cord neurites when presented with membranes pretreated with PI-PLC enzyme. The rostral neurites exhibit high randomness or lack of preference and thus differ significantly from the caudal neurites $(p<0.001)$. However, the rostral and caudal neurites do not show any significant preference for either set of membranes post PI-PLC enzyme treatment $(p=1)$. In Figure $4 C$, the analysis shows rostral spinal cord neurites grew preferentially on control membranes compared with PI-PLC-treated rostral membranes. In comparison the caudal spinal neurites show a significant preference for the PI-PLC treated rostral membranes over buffer treated control membranes $(p<0.001)$. In Figure $4 D$, PI-PLC pretreatment did not 


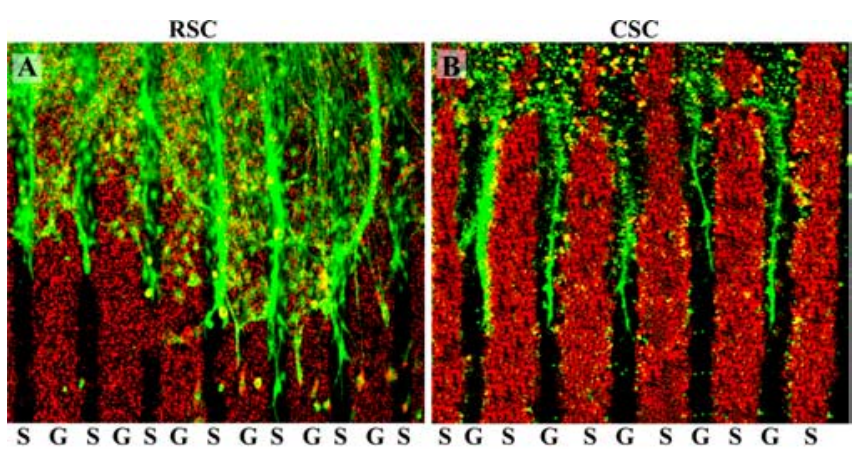

C Growth Preferences of Neurites on P0 Wild type Mice

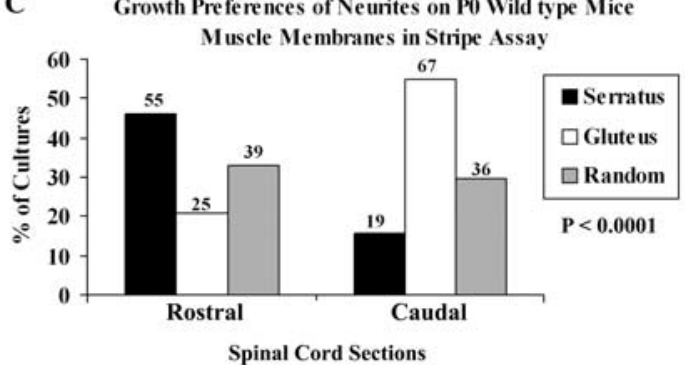

Figure 2. Position-dependent preferential outgrowth of E15 spinal neurites on membranes from P0 wild-type mice individual muscles. Spinal cord slices cut from the cervical [rostral spinal cord (RSC)] or lumbar [caudal spinal cord (CSC)] enlargement were placed on alternating stripes of membrane derived from the serratus anterior (S), a rostral muscle, or from the gluteus $(G)$, a caudal muscle. Membranes applied to one set of lanes in each culture were mixed with fluorescent beads to mark lane boundaries. After $3 \mathrm{~d}$, the cultures were fixed, and neurites were labeled with antibodies to neurofilaments. $A$, Rostral spinal cord neurites grew preferentially on serratus anterior membranes in $46 \%$ of cultures. $\boldsymbol{B}$, Caudal neurites grew selectively on gluteus membranes in $55 \%$ of cultures. C, Columns show the percentage of cultures showing preferential outgrowth on rostral (serratus anterior) or caudal (gluteus) membranes or no striking preference (random). Numbers indicate number of cultures in each category. A $\chi^{2}$ test for differences between rostral and caudal neurite outgrowth is highly significant: $p<0.0001$. Magnification: $A, 80 \times ; B, 100 \times$.

affect rostral neurite growth on caudal membranes. Whereas, selective caudal neurite growth on caudal membranes was slightly reduced by PI-PLC pretreatment, but not significantly ( $p=0.1$ ). The overall effect of PI-PLC enzyme treatment was more significant on rostral muscle membranes which are known to have higher expression of ephrin As.

In the third series of experiments, we tested the effect of blocking the ephrin A ligands present on muscle membranes with EphA fusion proteins on the selective outgrowth of neurites in vitro. EphA fusion bodies were added in solution to the muscle membrane stripes. The fusion bodies attach to the ephrin ligands on the membrane stripes and, thus, inhibit the ability of the Eph receptors on the subsequently growing neurites from interacting with the already occupied ephrin ligands on the membrane stripes.

Figure 5 illustrates the three media conditions that were used to test neurite selectivity: control media, media with added human Ig-Fc and media with EphA-Fc fusion proteins. Figure $5 \mathrm{~A}$ shows that in control media rostral neurites significantly prefer serratus anterior (SA) membranes over gluteus membranes. Conversely, caudal neurites strongly prefer gluteus membranes over SA membranes. This selective outgrowth is reproduced in media containing control human Ig-Fc (Fig. 5B). However, in the presence of EphA-Fc fusion proteins (Fig. 5C), this selectivity between SA and gluteus membranes is lost.

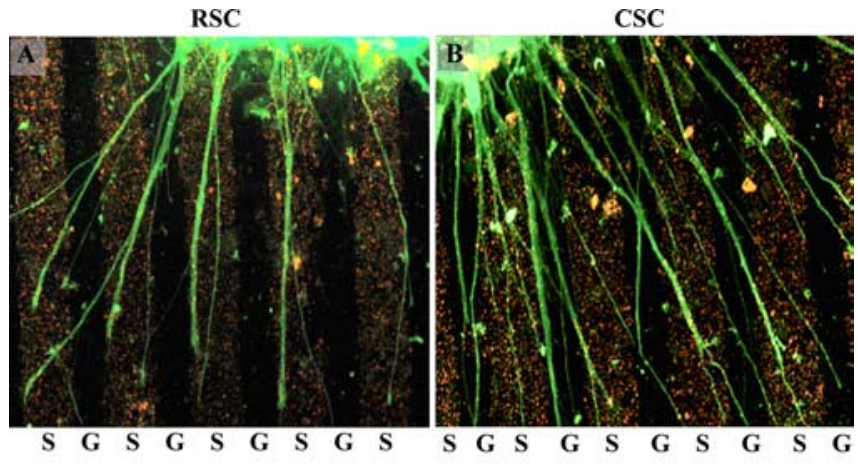

C Growth Preferences of Neurites on Knockout Muscle Membranes in Stripe Assay

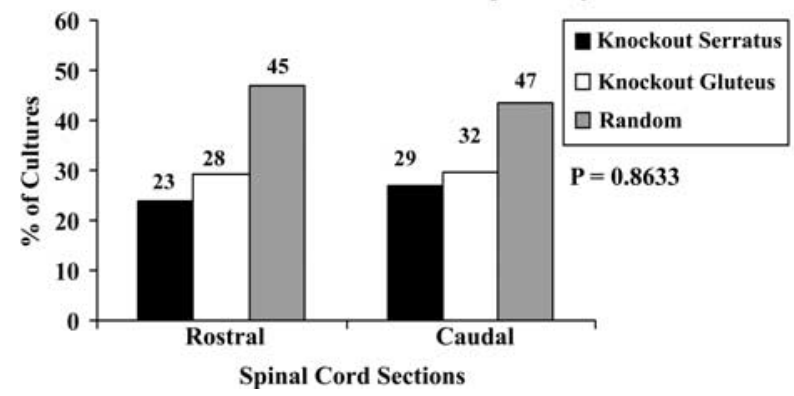

Figure 3. Position-dependent preferential outgrowth of $\mathrm{E} 15$ spinal neurites on membranes from P0 ephrin A2/A5 knock-out mice individual muscles. Spinal cord slices cut from the cervical [rostral spinal cord (RSC)] or lumbar [caudal spinal cord (CSC)] enlargement were placed on alternating stripes of membrane derived from the serratus anterior $(S)$, a rostral muscle, or from the gluteus $(G)$, a caudal muscle. Membranes applied to one set of lanes in each culture were mixed with fluorescent beads to mark lane boundaries. After $3 \mathrm{~d}$, the cultures were fixed and neurites were labeled with antibodies to neurofilaments. $A$, An example of rostral spinal cord neurites growing preferentially on serratus anterior membranes; this occurred in $23.95 \%$ of cultures. B, An example of caudal neurites growing randomly; this occurred in $43.51 \%$ of cultures. C, Columns show percentage of cultures showing preferential outgrowth on rostral (serratus anterior) or caudal (gluteus) membranes or no striking preference (random). Overall ( $(\boldsymbol{C}$, rostral spinal cord neurites grew preferentially to the same extent on SA (24\%) and gluteus (29\%) membranes. Similarly, caudal neurites grew preferentially to the same extent on either SA (27\%) or gluteus membranes (29\%). In both types of cultures there is an increase in the percentage of neurites showing no striking preference (random) compared with wild-type membranes (Fig. 2). This indicates no strong preference of neurite outgrowth on mutant muscle membranes from their corresponding axial position. Numbers indicate number of cultures in each category. $A \chi^{2}$ test for differences between rostral and caudal neurite outgrowth is not significant: $p=0.8633$. Magnification: $A, B, 120 \times$

\section{Selective growth of neurites on membranes from different} sectors within an individual diaphragm muscle

In these experiments we asked whether growing neurites from spinal cord slices could detect a difference between membranes from rostral and caudal portions of the same muscle.

In the first experiment, membranes from rostral sectors (1-4) and caudal sectors (5-8) of P0 mouse diaphragm muscles were arrayed in alternating lanes as described in Materials and Methods. Slices of rat spinal cord from the cervical or lumbar enlargement (called rostral and caudal here, respectively) (Fig. 1) were placed atop the membranes, so neurites had equal access to both types of lanes. Two cultures from this series are illustrated in Figure 6, $A$ and $B$, and results from all 331 cultures in this series are summarized in Figure $6 C$. In $\sim 60 \%$ ( 101 of 162 ) of the cultures made with rostral cervical spinal cord slices, neurites showed a striking preference for rostrally derived membranes (Fig. 6A, C). In 29\% (43 of 162) of the remaining rostral spinal cord cultures, neurites crossed between lanes and showed no striking preference. Caudal sector membranes were the preferred substrate in $11 \%$ of cultures (18 of 162). Thus, rostrally 


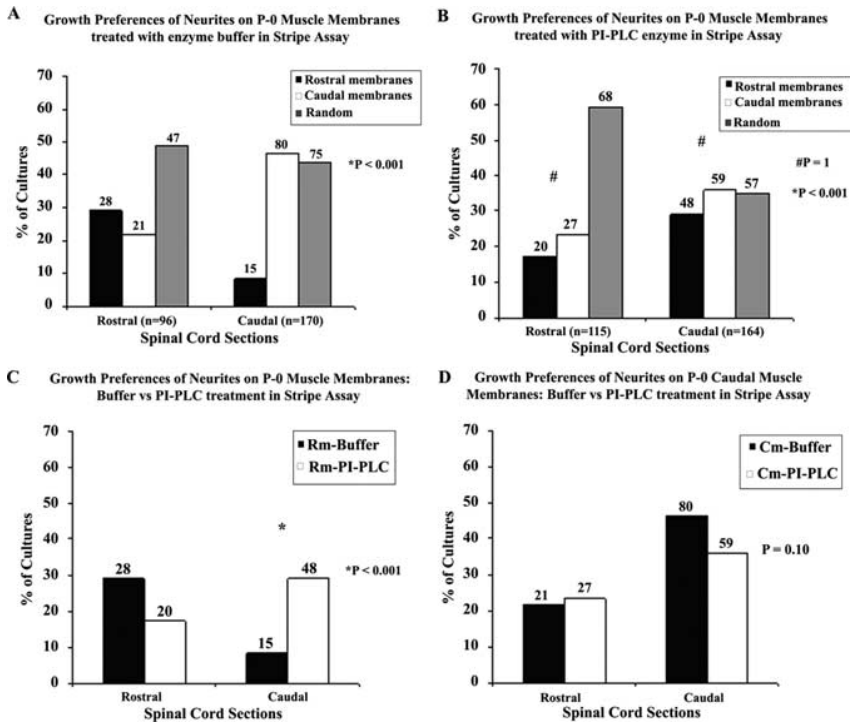

Figure 4. Position-dependent preferential outgrowth of E15 spinal cord neurites on membranes from PO limb muscles treated with PI-PLC and enzyme buffer. Spinal cord slices cut from the cervical [rostral spinal cord (RSC)] or lumbar [caudal spinal cord (CSC)] enlargement were placed on alternating stripes of membrane derived from rostral muscles, or from caudal muscles which were pretreated with PI-PLC enzyme or buffer for controls. A, Columns show the percentage of cultures showing preferential outgrowth on rostral or caudal membranes treated with enzyme buffer. Numbers above each column indicate the number of cocultures observed for each category. $A \chi^{2}$ test for differences between rostral and caudal neurite outgrowth on buffer treated membranes is highly significant: $p<0.001$. B Columns show percentage of cultures showing preferential outgrowth on rostral or caudal membranes treated with PI-PLC enzyme. Numbers above each column indicate number of cocultures observed for each category. A $\chi^{2}$ test for overall differences between rostral and caudal neurite outgrowth on PI-PLC enzyme treated membranes is highly significant: $p<0.001$ whereas a $\chi^{2}$ test for differences between rostral and caudal neurite outgrowth growing selectively on either PI-PLC enzyme treated membranes is not significant: $p=1$. C, Columns show the percentage of cultures showing preferential outgrowth on rostral membranes treated with PI-PLC enzyme or buffer. Numbers above each column indicate number of cocultures observed for each category. A $\chi^{2}$ test for differences between rostral and caudal neurite outgrowth on PI-PLC enzyme or buffer treated rostral membranes is highly significant: $p<0.001$. D, Columns show the percentage of cultures showing preferential outgrowth on caudal membranes treated with PI-PLC enzyme or buffer. Numbers above each column indicate number of cocultures observed for each category. A $\chi^{2}$ test for differences between rostral and caudal neurite outgrowth on PI-PLC enzyme or buffer treated caudal membranes is not significant: $p=0.10$.

derived spinal neurites prefer membranes from rostral sectors to caudal sectors within an individual muscle.

The outgrowth of neurites from caudal spinal cord was different from that of rostral neurites. Caudal neurites preferred caudal diaphragm muscle membranes in 60\% (101 of 169) of the cultures (Fig. 6B, $C$ ), preferred rostral sector membranes in $12 \%(20$ of 169 ) of the cultures, and showed no clear preference in $\sim 28 \%$ (48 of 169) of the cultures. Thus, preferences of caudal neurites were biased toward caudal diaphragm muscle membranes.

Selective growth of neurites from two distinct axial positions within the cervical spinal cord

In the previous set of experiments, we tested the growth preference of neurites from two distinct spinal cord segments, cervical (rostral) and lumbar (caudal), on membranes from rostral and caudal halves of a single muscle, the diaphragm. However, in vivo developing axons from the lumbar motor pool never encounter the diaphragm muscle to innervate it. Rather, the diaphragm is innervated by a motor pool within the cervical spinal cord. Hence, we tested the outgrowth of neurites from the rostral $\left(\mathrm{C}_{1}-\right.$ $\left.\mathrm{C}_{2}\right)$ and caudal $\left(\mathrm{C}_{6}-\mathrm{C}_{8}\right)$ ends of the cervical spinal cord. Figure 7

\section{A Growth Preferences of E15 Spinal Cord Neurites on P0 Muscle} Membranes in Control media in Choice assay

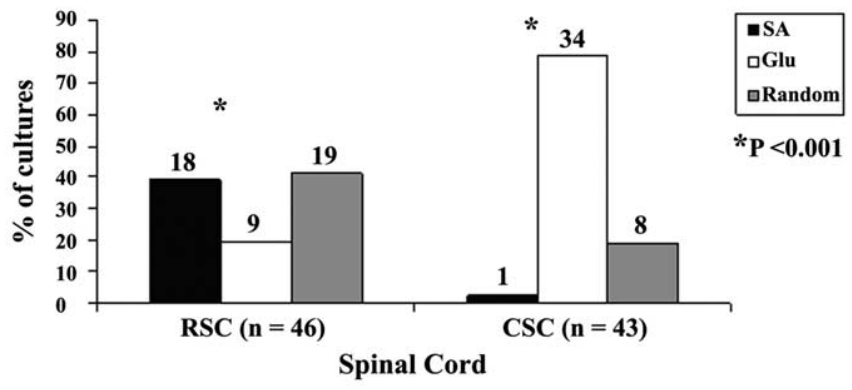

B Growth Preferences of E15 Spinal Cord Neurites on P0 Muscle Membranes in Human Ig-Fc media in Choice assay

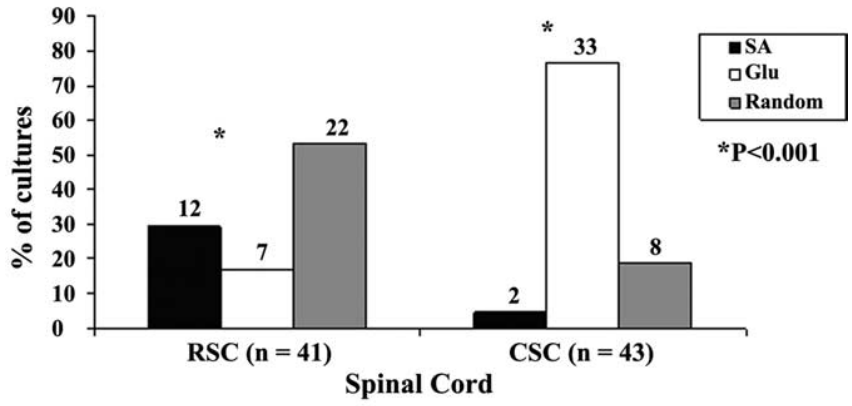

\section{$C_{\text {Growth Preferences of E15 Spinal Cord Neurites on P0 Muscle }}$} Membranes in EphA-Fc proteins in media in Choice assay

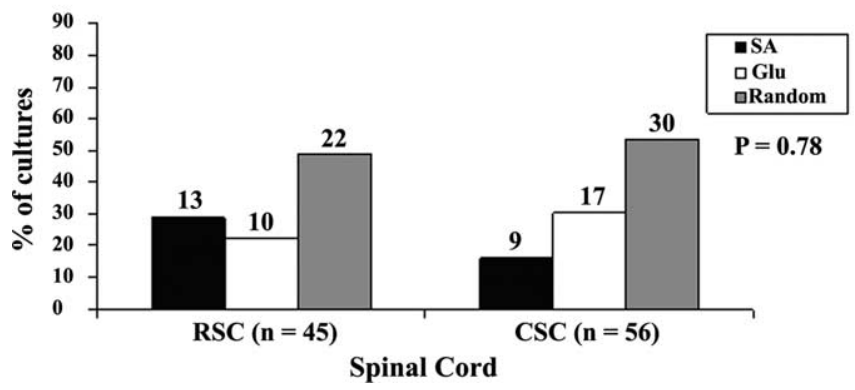

Figure 5. EphA fusion proteins reduce the selectivity of spinal neurites on muscle membranes. E15 spinal cord neurites were tested in the "choice assay" in which alternate lanes of rostral $(S A)$ or caudal (gluteus) membranes were arrayed. The results testing the three media conditions are shown. $\boldsymbol{A}$, Results of selective outgrowth in control media similar to Figure 2. $\boldsymbol{B}$ illustrates similar selectivity in media containing human Ig-Fc proteins. C, Loss in selectivity in media containing EphA-Fc. Numbers above each column indicate number of cocultures observed for each category. A $\chi^{2}$ test for differences between rostral and caudal neurite outgrowth on serratus and gluteus muscles in control media and media with human Ig-Fc is significant $(p<0.001)$ whereas the outgrowth in media with EphA-Fc is not significant $(p=0.78) .{ }^{*} p<0.001$.

illustrates the results from a total of 356 cultures. Neurites from caudal $\left(\mathrm{C}_{6}-\mathrm{C}_{8}\right)$ cervical spinal cord explants $(n=186)$ grew preferentially on caudal sector membranes in $48 \%$ of cultures ( 87 of 186) (Fig. $7 \mathrm{~B}, \mathrm{C}$ ), extended preferentially on rostral sector membranes in $17 \%(33 / 186)$ of cultures and grew randomly in $35 \%$ ( 66 of 186). In contrast, neurites from rostral $\left(C_{1}\right.$ or $\left.C_{2}\right)$ cervical spinal cord explants grew preferentially on rostral sector membranes in 55\% of cultures ( 94 of 170) (Fig. $7 \mathrm{~A}, \mathrm{C}$ ), extended preferentially on caudal sector membranes in only $11 \%$ (19 of 170 ), or grew randomly in the remaining 33\% (57 of 170). Thus, neurites from rostral or caudal edges of one region of the spinal cord 

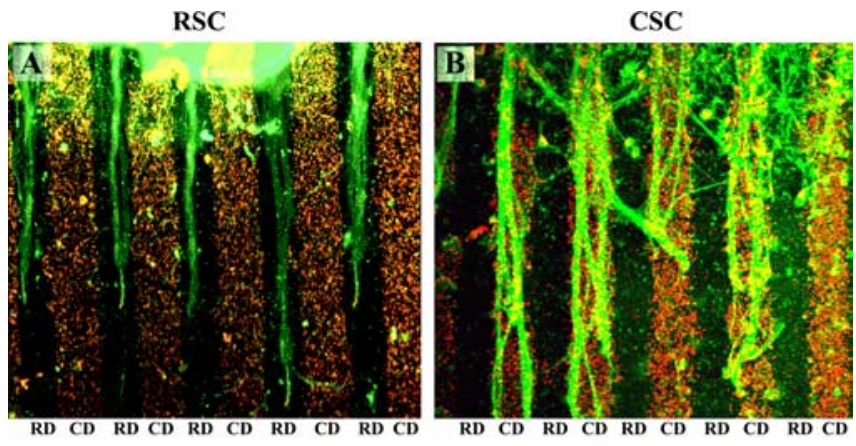

\section{Growth Preferences of Neurites on P-0 Diaphragm Membranes in Stripe Assay}

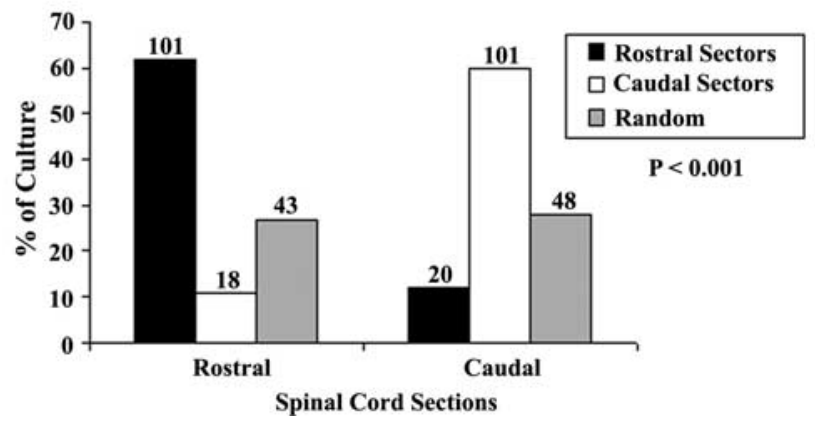

Figure 6. Position-dependent preferential outgrowth of spinal neurites on membranes from rostral or caudal halves of the diaphragm. Cervical spinal cord slices [rostral spinal cord (RSC)] or lumbar cord slices [caudal spinal cord (CSC)] were cocultured on alternating lanes of membranes from rostral diaphragm (RD) or caudal diaphragm (CD) muscles. $A$, RCS neurites grow preferentially on lanes of membranes from rostral diaphragm in $60 \%$ of cultures. $B$, CSC neurites grow preferentially on lanes of membranes from caudal diaphragm in $60 \%$ of cultures. C, Columns show percentage of cultures showing preferential outgrowth on membranes from rostral sectors or caudal sectors of diaphragm muscle or no striking preference (random). Numbers indicate number of cultures in each category. $A \chi^{2}$ test for differences between rostral and caudal neurite outgrowth is highly significant $(p<0.001)$. Magnification: $A, B, 120 \times$.

(cervical) can detect differences between membranes derived from rostral or caudal halves of a single muscle, the diaphragm.

\section{Selective growth of neurites from each segment of cervical} spinal cord

Next, we tested the outgrowth of neurites from all the segments $\left(\mathrm{C}_{1}-\mathrm{C}_{8}\right)$ within the cervical spinal cord. That is, each cervical cord segment was cultured on alternating stripes of rostral or caudal diaphragm muscle membranes. A total of 394 cocultures were analyzed in this study. In this set of cultures, preferences were similar to those documented above for P0 mouse diaphragm muscle membranes (Fig. 7). Rostral cervical neurites from $\mathrm{C}_{1}-\mathrm{C}_{3}$ demonstrated a clear preference for rostral diaphragm membranes, whereas caudal cervical segments $\mathrm{C}_{5}-\mathrm{C}_{8}$ had a striking preference for the caudal muscle membranes (Fig. $8 \mathrm{~A}$ ). Neurites from cervical segment $\mathrm{C}_{4}$ showed no clear preference for any sector, growing randomly in $>70 \%$ of cocultures (Fig. $8 \mathrm{~B}$ ). Figure 8 also demonstrates that selectivity diminishes at the extreme rostral and caudal edges of the cervical spinal cord.

\section{Endogenous expression of ephrin As in the neonatal} diaphragm muscle

In an effort to determine whether the diaphragm muscle expresses ephrin As as a rostral to caudal gradient, we conducted RT-PCR
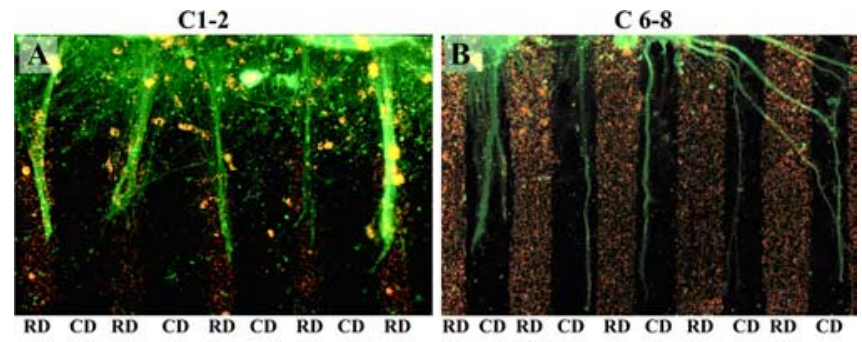

\section{Growth Preferences of Cervical Pool Neurites on P-0} Diaphragm Membranes in Stripe Assay

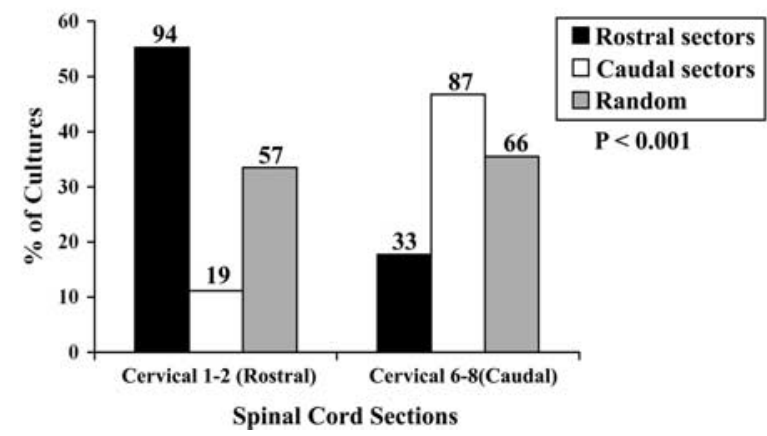

Figure 7. Position-dependent preferential outgrowth of cervical spinal neurites on membranes from rostral or caudal halves of the diaphragm. Rostral cervical segments (C1-C2) were compared with caudal cervical segments ( $(6-C 8)$ by coculturing on alternating lanes of membranes from rostral diaphragm (RD) or caudal diaphragm (CD) muscles. $A$, Rostral cervical neurites (C1-C2) grow preferentially on rostral diaphragm membranes in $55 \%$ of cultures. B, Caudal cervical neurites (C6-C8) grow preferentially on caudal diaphragm membranes in $48 \%$. C, Columns show the percentage of cultures showing preferential outgrowth on membranes from rostral sectors or caudal sectors of diaphragm muscle or no striking preference (random). Numbers indicate number of cultures in each category. A $\chi^{2}$ test for differences between rostral cervical (C1-C2) and caudal cervical (C6-C8) neurite outgrowth is highly significant ( $p<$ 0.001). Magnification: $A, B, 140 \times$.

experiments on diaphragms of $\mathrm{P} 0$ mouse pups. Table 3 presents the data based on 67 diaphragms collected from nine litters.

All five ephrin As (1-5) were expressed in the diaphragm quadrants to varying degrees. Ephrins A1, A2, and A5 are significantly higher in the caudal region 4 than rostral region 1. Ephrin A4 has a $U$ shape expression with both outer $(1,4)$ regions showing significantly higher expression than the central $(2,3)$ regions. Ephrin A3 is only weakly expressed in the diaphragm, and no rostral to caudal differences were observed. These data indicated a gradient of expression of four of the five ephrin As in the diaphragm, and prompted the investigation of selective growth of neurites on muscle membranes of mice with deletion of the ephrin $\mathrm{A} 2$ and $\mathrm{A} 5$ genes.

\section{Selective growth of neurites on diaphragm membranes of} ephrin A2-/- ephrin A5-/- double mutant mice

We next asked whether the selective growth of cervical spinal cord neurites on diaphragm muscle membranes was dependent on the endogenous expression of ephrin A ligands. We examined the outgrowth of neurites from the rostral $\left(\mathrm{C}_{1}-\mathrm{C}_{2}\right)$ and caudal $\left(\mathrm{C}_{6}-\mathrm{C}_{8}\right)$ spinal cord slices on diaphragm membranes taken from ephrin A2-/- ephrin A5-/- double mutant mice. In this set of cultures, preferences were different from those documented above for wild-type $\mathrm{P} 0$ mouse diaphragm muscle membranes (Fig. 7). Neurites from caudal $\left(\mathrm{C}_{6}-\mathrm{C}_{8}\right)$ cervical spinal cord explants $(n=154)$ extended preferentially on caudal sector membranes in $27 \%$ of cultures ( 42 of $154 ; 27 \%$ ) whereas $23 \%$ of the 
A

\section{Growth Preferences of Cervical Pool Neurites on P-0 Diaphragm Membranes in Stripe Assay}

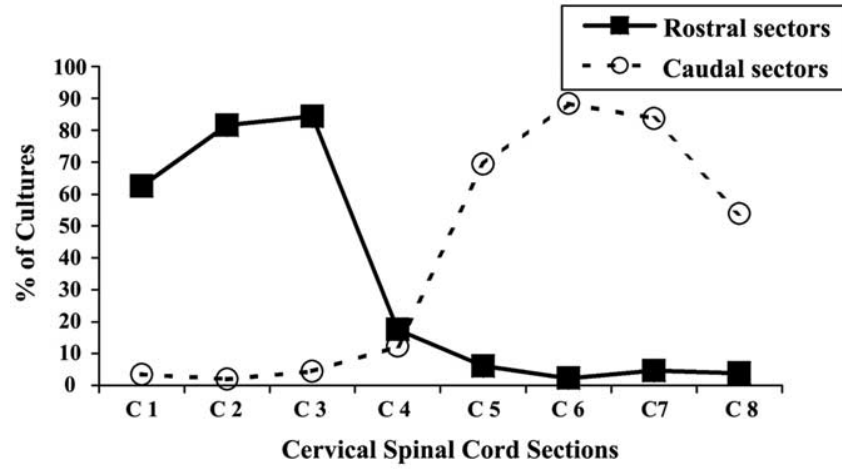

B

\section{Growth Preferences of Cervical Pool Neurites on} P-0 Diaphragm Membranes in Stripe Assay

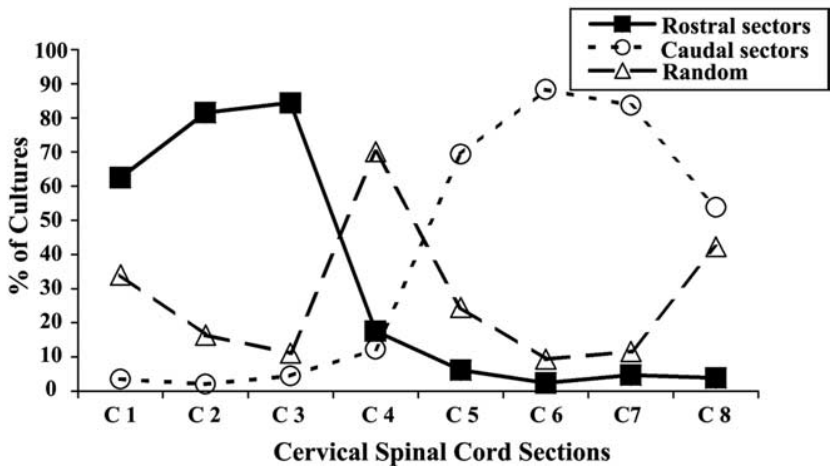

Figure 8. Positional-dependent cervical spinal neurites outgrowth on membranes isolated from rostral or caudal halves of the diaphragm muscle. The cervical region of the E15 rat spinal cord was isolated and cut into individual segments from $C_{1}$ to $C_{8}$. Cervical cord slices were cocultured on alternating lanes of membranes from rostral diaphragm (RD) or caudal diaphragm (CD) muscles as in Figure 7. $A$, The percentage of cultures in which neurites of each segment grew preferentially on rostral diaphragm membranes (rostral sectors, filled squares) or caudal diaphragm membranes (caudal sectors, open circles). $\boldsymbol{B}$, The same data as in $\boldsymbol{A}$, but includes those cocultures where growth was "random" (open triangles).

cultures (36 of 154; 23\%) preferred rostral sector membranes (Fig. 9). Nearly $50 \%$ of cultures grew randomly (76 of 154), thereby exhibiting no significant preference overall for any sector. Similarly, neurites from rostral $\left(\mathrm{C}_{1}-\mathrm{C}_{2}\right)$ cervical spinal cord explants grew preferentially on rostral sector membranes in $27 \%$ of cultures (37 of 136), extended preferentially on caudal membranes in 26\% (36 of 136) or grew randomly in the remaining $47 \%$ (63 of 136). A $\chi^{2}$ analysis of the differences in selective outgrowth between rostral and caudal neurites was applied. The null hypothesis that rostral and caudal neurites exhibited no difference in selective outgrowth was accepted. These results indicate a clear loss in the preferential outgrowth of cervical spinal cord neurites on membranes from diaphragm of A2 - / - ephrin A5-/- double mutant mice.

\section{Discussion}

Previous results from our lab have shown that motor pools innervate target muscles forming distinct rostrocaudal topographic maps. In an effort to define the molecular mechanisms underlying these topographic maps, we have previously reported the preferential growth of cervical spinal neurites (rostral) on rostral muscle membranes. In contrast, lumbar neurites (caudal) preferred growth on caudal muscle membranes (Wang et al., 1999,
2001; Feng et al. 2000). Although instructive, this experimental design did not reproduce the in vivo situation wherein neurites within a single motor pool are able to detect topographic differences within a single appropriate target muscle. The results reported here address this question directly: Do cervical spinal cord neurites detect differences between membranes from rostral and caudal portions of an appropriate target muscle, the diaphragm? The answer is yes.

The results lead us to seven general conclusions. First, when comparing spinal neurites from two separate areas of the neuraxis, that is cervical and lumbar, cervical neurites prefer to grow on membranes derived from the rostral half of the diaphragm, whereas lumbar neurites prefer caudal diaphragm membranes. Second, this selectivity is even observed within a single region of the spinal cord, the cervical region, onto a single target muscle, the diaphragm. Thus rostral cervical segments $\left(\mathrm{C}_{1}\right.$ and $\mathrm{C}_{2}$ ) prefer to grow on rostral diaphragm membranes; whereas caudal segments $\left(\mathrm{C}_{6}-\mathrm{C}_{8}\right)$ prefer caudal diaphragm membranes. Third, when each segment of the cervical spinal cord $\left(C_{1}\right.$ to $\left.C_{8}\right)$ was tested for selective outgrowth, there was a gradual transition of preferential growth from rostral to caudal segments of the cervical spinal cord. Fourth, all five ephrin As are expressed in the SA and gluteus muscles, with higher levels of A2, A4, and A5 in the SA. Fifth, all five ephrin A ligands are expressed in the diaphragm, and $\mathrm{A} 1, \mathrm{~A} 2$, and $\mathrm{A} 5$ are expressed in higher amounts in caudal regions of the muscle than in rostral whereas A4 is expressed more in both rostral and caudal ends of the diaphragm. Sixth, consistent with previous in vitro and physiological observations, deletion of the genes for ephrins A2 and A5 reduced the ability of rostral and caudal neurites to grow preferentially on membranes of corresponding axial position. Seventh, blocking the ephrin ligands with Eph fusion proteins on the muscle membranes and cleaving of the ephrin ligands with PI-PLC from the muscle membranes reduced the ability of the spinal cord neurites to grow preferentially on membranes of corresponding axial position. These results demonstrate for the first time selective choices for positionally matched growth made by segmentally appropriate spinal neurites in vitro. Moreover, they support the significant role played by the Eph/ephrin A kinase system in this positional selectivity.

\section{A gradient of selectivity within the cervical spinal cord}

Rostral cervical spinal neurites arising from segments $C_{1}$ to $C_{3}$ strongly prefer rostral diaphragm membranes. Conversely, segments $\mathrm{C}_{5}$ to $\mathrm{C}_{8}$ strongly prefer caudal muscle membranes. Cervical segment $\mathrm{C}_{4}$ is transitional, showing mostly random growth. Using retrograde labeling with fluorescent dyes, we showed previously that the motor pool innervating the mouse diaphragm encompasses $\mathrm{C}_{3}$ to $\mathrm{C}_{7}$ (Feng et al., 2000). Physiologically we found that cervical ventral roots $\mathrm{C}_{4}$ to $\mathrm{C}_{6}$ are the principal source of innervation of the diaphragm in both rat and mouse (Laskowski and Sanes, 1987) (M. B. Laskowski, unpublished observation). Thus, it is reasonable to propose that cervical segments $\mathrm{C}_{3}$ to $\mathrm{C}_{7}$ of the mouse spinal cord contain the motor pool for the mouse diaphragm. Referring to Figure $8 \mathrm{~A}, \mathrm{~B}$, segment $\mathrm{C}_{5}-\mathrm{C}_{7}$ clearly prefer caudal membranes, whereas more rostral segments of the phrenic motor pool either display no preference $\left(\mathrm{C}_{4}\right)$ or a rostral bias $\left(\mathrm{C}_{3}\right)$. This implies that within the phrenic motor pool there is a topographic bias, with a strong preference for caudal regions of the muscle. Presumably segments $\mathrm{C}_{1}$ and $\mathrm{C}_{2}$ lie outside of the phrenic motor pool. Yet neurites from these segments show strong preference for rostral diaphragm membranes. This 
Table 3. Endogenous expression of ephrin As in diaphragm muscle regions

\begin{tabular}{lcccr}
\hline $\begin{array}{l}\text { Diaphragm } \\
\text { sector }\end{array}$ & 1 & 2 & 3 & 4 \\
Rostralmost & & & Caudalmost \\
\hline $\begin{array}{l}\text { Ephrin A } \\
\text { A1* }\end{array}$ & $6.1 \pm 1.6$ & $7.5 \pm 1.1$ & $7.2 \pm 1.2$ & $9.4 \pm 0.48$ \\
$\mathrm{~A} 2^{*}$ & $4.6 \pm 1.5$ & $4.7 \pm 0.56$ & $4.7 \pm 0.84$ & $6.2 \pm 0.47$ \\
$\mathrm{~A} 3$ & $0.17 \pm 0.10$ & $0.14 \pm 0.05$ & $0.41 \pm 0.49$ & $0.30 \pm 0.10$ \\
$\mathrm{~A} 4^{* *}$ & $1.8 \pm 0.7$ & $1.5 \pm 0.35$ & $1.4 \pm 0.22$ & $1.8 \pm 0.19$ \\
$\mathrm{~A} 5^{*}$ & $21 \pm 5.9$ & $21 \pm 4.6$ & $23 \pm 2.3$ & $33 \pm 6.3$ \\
\hline
\end{tabular}

${ }^{*} p<0.001$ sectors 1 versus $4 ;{ }^{* *} p<0.05$ combining outer sectors 1 and 4 versus central sectors 2 and 3 .

Growth Preferences of Cervical Pool Neurites on P-0 Knockout Diaphragm Membranes in Stripe Assay

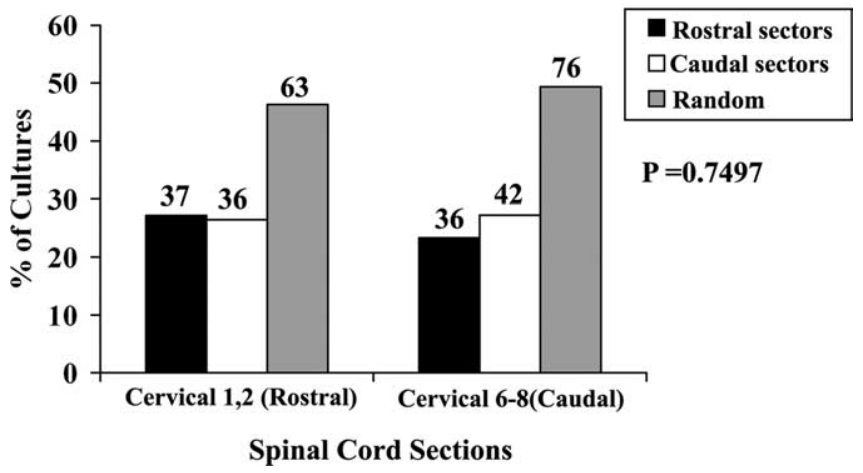

Figure 9. Position-dependent preferential outgrowth on membranes isolated from rostral or caudal diaphragm of the ephrin A2, A5 mutant mouse. Cervical rostral (C1-C2) or caudal (C6-C8) spinal cord slices were cocultured with alternating lanes of membranes from rostral diaphragm (RD) or caudal diaphragm (CD) muscles of mice in which the genes for ephrin A2 and A5 have been deleted. Columns show the percentage of cultures showing preferential outgrowth on membranes from rostral sectors or caudal sectors of diaphragm muscle or no striking preference (random). In the "random" category are included cultures where neurite growth was truly random, as well as cultures with selective growth that did not fit our strict criteria. Numbers indicate number of cultures in each category. $\mathrm{A} \chi^{2}$ test for differences between rostral cervical (C1-C2) and caudal cervical (C6-C8) neurite outgrowth is not significant ( $p=0.749$ ).

suggests that the gradient of selectivity extends beyond the limits of the diaphragm's motor pool.

\section{Comparing neurite selectivity on muscle membranes}

Three regions of the spinal cord were studied in this series of experiments: rostral cervical (primarily $\mathrm{C}_{1}-\mathrm{C}_{4}$ ), caudal cervical $\left(\mathrm{C}_{6}-\mathrm{C}_{8}\right)$, and lumbar $\left(\mathrm{L}_{1}-\mathrm{S}_{1}\right)$. In addition, the cervical cord $\left(\mathrm{C}_{1}-\mathrm{C}_{8}\right)$ was analyzed systematically.

Cervical regions $\mathrm{C}_{1}-\mathrm{C}_{8}$ had a strong preference for SA over gluteus muscle membranes. This preference was eliminated in membranes from ephrin A2, A5 mutant mouse muscles. This preference by $\mathrm{C}_{1}-\mathrm{C}_{8}$ neurites for $\mathrm{SA}$ membranes was also reduced with PI-PLC pretreatment and EphA fusion proteins. This region also had a general preference for rostral regions of the diaphragm. The selectivity for diaphragm regions was also reduced in membranes of ephrin A2, A5 knock-out muscle. Thus, neurites originating in the rostral cervical spinal cord respond to ephrin As in muscle membranes, especially A2 and A5.

Within the Cervical region, when distinct rostral cervical $\mathrm{C}_{1}-\mathrm{C}_{2}$ and caudal cervical region $\mathrm{C}_{6}-\mathrm{C}_{8}$ are cultured they exhibit preferential outgrowth on membranes of corresponding axial position within a single muscle, the diaphragm. This selectivity was also sensitive to the presence of ephrin A2, A5, because selectivity was reduced in membranes of ephrin A2, A5 mutant diaphragm.

Lumbar spinal neurites $\left(\mathrm{L}_{1}-\mathrm{S}_{1}\right)$ preferred to grow on gluteus membranes over SA membranes, and on caudal diaphragm over rostral diaphragm. The preference of lumbar neurites for gluteus muscle membranes was reduced in ephrin A2, A5 mutant membranes, with pretreatment with PI-PLC or with the addition of EphA fusion proteins.

We reported previously that ephrin mRNA levels are comparable at E16, E18, and $\mathrm{P} 0$, and are significantly decreased in the adult (Feng et al., 2000). We also shown that E15 spinal cord neurites have similar preferential outgrowth on E18 muscles as well as neonate muscles (P0) (Wang et al., 1999). For all of our work we use E15 spinal cord explants because it is the approximate time when motor neurons leave the spinal cord and make first contact with the target muscles.

\section{The role of ephrin As in neuromuscular topography}

Together, these results demonstrate a significant role for ephrin As, particularly A2 and A5, in the neuromuscular topography of these three muscles. What is the role of the gradients in some of the ephrin As that we report here? Although the gradients of ephrin As are significant from rostral to caudal regions of the diaphragm and between the SA and gluteus muscles, the role that individual ephrin A ligands play in neuromuscular topography is not clear at this time. What we do know is that in general the ephrin As that we have tested are inhibitory to spinal cord neurites from all levels of the neuraxis we have studied, but with varying degrees of sensitivity. This overall inhibitory role of ephrin As is based on three observations. First, both cervical and lumbar spinal cord neurites avoid lanes containing ephrin A5, especially caudal neurites (Wang et al., 1999, 2001). Second, we report that the avoidance of muscle membranes from a distant region of the neuraxis is reduced in ephrin A2, A5 mutant mice. Third, the avoidance of membranes is reduced with the addition of EphA fusion proteins or with PI-PLC pretreatment.

It is also possible that different subsets of motor neurons respond differently to ephrin As in their environment. For example, Eberhart et al. (2004) have shown that, in the embryonic chick hindlimb, EphA4-positive axons from lateral motor column motor neurons [LMC(1)] avoid ephrin A5-positive hindlimb mesoderm. But Eph-positive axons from medial motor column neurons $[\mathrm{MMC}(\mathrm{m})]$ are attracted to ephrin A5-positive rostral half-sclerotome. Conceivably, a similar attraction/repulsion mechanism could occur in our system, but this must await markers for distinct subsets of mammalian motor neurons.

\section{An ephrin A model for topographic specificity}

To account for these observations we propose that ephrin As impose an overall inhibitory background to neurite growth. Superimposed on this inhibitory model we propose attractive factors, as yet unidentified, that select for the relative position of spinal neurites within the neuraxis.

The data presented in this report are consistent with a model (Fig. 10) in which rostral and caudal neurites respond to both attractive and repulsive factors on the three muscles we have studied. We propose that one or more ephrin As comprise the inhibitory rostral $\left(\mathrm{I}_{\mathrm{R}}\right)$ and inhibitory caudal $\left(\mathrm{I}_{\mathrm{C}}\right)$ factors as shown in Figure 10. We further propose that both rostral and caudal neurites are repulsed by A2 and/or A5 in particular. The model also proposes rostral and caudal attractive factors $\left(A_{R}\right.$ and $\left.A_{C}\right)$. We can only speculate on the identity of these attractive factors, but we propose them as necessary to account for our results. Even 
A Multifactor Model for Topography

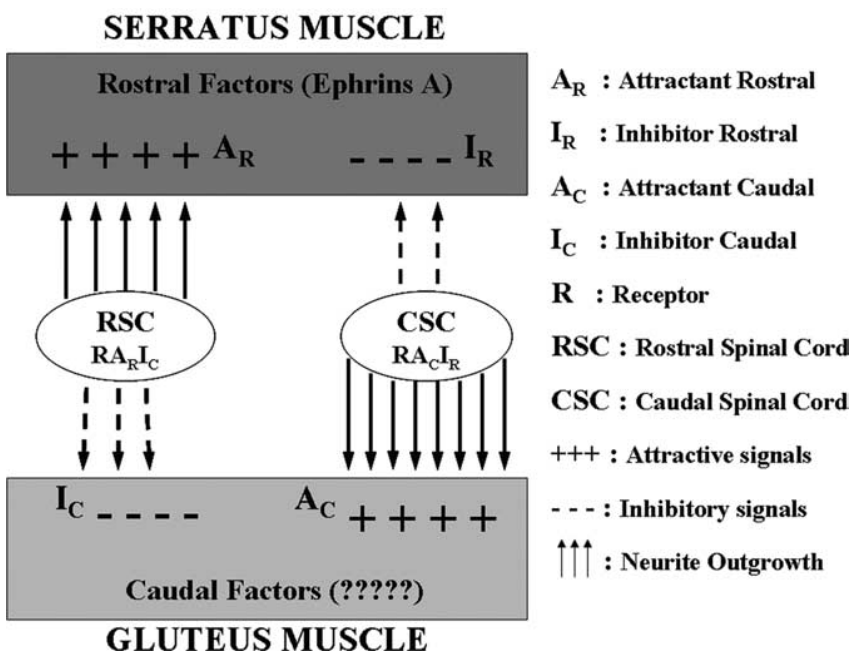

Figure 10. A "multifactor" model for topography. A schematic representation of the interplay of guidance factors involved in the topographic innervation of the muscles is shown. Here, we propose that ephrin As impose an overall inhibitory background to neurite growth. Superimposed on this inhibitory model we propose attractive factors, as yet unidentified, that select for the relative position of spinal neurites within the neuraxis. On the left, RSC neurites are attracted by a rostral factor $\left(A_{R}\right)$, but repulsed by a caudal inhibitory factor $\left(I_{C}\right)$. On the right, CSC neurites are attracted by a caudal attractant factor $\left(A_{C}\right)$, but inhibited by an $I_{C}$.

in the presence of ephrin A fusion proteins or after PI-PLC treatment, some selective outgrowth remains.

How can we reconcile the observation that caudal cervical neurites grow selectively on caudal regions of the diaphragm, a region which we have shown has higher endogenous levels of ephrin A1, A2, A4, and A5? Considered from the perspective of growing neurites, $\mathrm{C}_{6}-\mathrm{C}_{8}$ neurites preferred $\mathrm{SA}$ membranes, also with high ephrin A expression. We know from these results that when membranes are depleted of ephrins A2 and A5, cervical neurites are less selective in their outgrowth. This is consistent with physiological studies (Feng et al., 2000) that show an altered topographic map in diaphragms of A2, A5 mutant mice. Applying the model within the diaphragm muscle, however, will require more detailed experiments on the role of individual ephrins in selective neurite outgrowth. We have provided an important starting point in these studies by demonstrating selective neurite outgrowth by individual spinal cord segments within the phrenic motor pool.

In summary, the ephrin As, and especially ephrins A2 and A5, play an important role in topographic choices made by growing neurites on diaphragm and other muscle membranes. But to explain our results these ephrins must be accompanied by additional cues, one of which we propose to be the aforementioned "attractive factor(s)." It is reasonable that in the three muscles studied, a combination of ephrin A ligands and one or more positional cues yet to be identified could together account for the development of neuromuscular topographic map.

\section{References}

Bennett MR, Lavidis NA (1984) Development of the topographical projection of motor neurons to a rat muscle accompanies loss of polyneuronal innervation. J Neurosci 4:2204-2212.

Bradford MM (1976) A rapid and sensitive method for the quantitation of microgram quantities of protein utilizing the principle of protein-dye binding. Anal Biochem 72:248-254.
Brown MC, Booth CM (1983a) Segregation of motor nerves on a segmental basis during synapse elimination in neonatal muscles. Brain Res 273:188-190.

Brown MC, Booth CM (1983b) Postnatal development of the adult pattern of motor axon distribution in rat muscle. Nature 304:741-742.

Chadaram SR, Laskowski MB (2003) Denervation and age modify neuromuscular positional selectivity. J Neurobiol 56:347-359.

Donoghue MJ, Lewis RM, Merlie JP, Sanes JR (1996) The Eph kinase ligand AL-1 is expressed by rostral muscles and inhibits outgrowth from caudal neurons. Mol Cell Neurosci 8:185-198.

Drescher UC, Kremoser C, Handwerker C, Loschinger J, Noda M, Bonhoeffer F (1995) In vitro guidance of retinal ganglion cell axons by RAGS, a 25 $\mathrm{kDa}$ tectal protein related to ligands for Eph receptor tyrosine kinase. Cell 82:359-370.

Eberhart J, Barr J, O’Connell S, Flagg A, Swartz ME, Cramer KS, Tosney KW, Pasquale EB, Krull CE (2004) Ephrin-A5 exerts positive or inhibitory effects on distinct subsets of EphA4-positive motor neurons. J Neurosci 24:1070-1078.

Feng G, Laskowski MB, Feldheim DA, Wang H, Lewis R, Frisen J, Flanagan JG, Sanes JR (2000) Roles for ephrins in positionally selective synaptogenesis between motor neurons and muscle fibers. Neuron 25:295-306.

Flanagan JG (2006) Neural map specification by gradients. Curr Opin Neurobiol 16:59-66.

Huber AB, Kolodkin AL, Ginty DD, Cloutier JF (2003) Signaling at the growth cone: ligand-receptor complexes and the control of axon growth and guidance. Annu Rev Neurosci 26:509-563.

Iwamasa H, Ohta K, Yamada T, Ushijima K, Terasaki H, Tanaka H (1999) Expression of Eph receptor tyrosine kinases and their ligands in chick embryonic motor neurons and hindlimb muscles. Dev Growth Differ 41:685-698.

Kilpatrick TJ, Brown A, Lai C, Gassamnn M, Goulding M, Lamke G (1996) Expression of the Tyro 4/Mek 4/cek 4 gene specifically marks a subset of embryonic motor neurons and their muscle targets. Mol Cell Neurosci 7:62-74.

Knoll B, Drescher U (2002) Ephrin-As as receptors in topographic projections. Trends Neurosci 25:145-149.

Laskowski MB, High JA (1989) Expression of nerve-muscle topography during development. J Neurosci 9:175-182.

Laskowski MB, Sanes JR (1987) Topographic mapping of motor pools onto skeletal muscles. J Neurosci 7:252-260.

Nakamoto M, Cheng HJ, Friedman GC, McLaughlin T, Hansen MJ, Yoon CH, O'Leary DD, Flanagan JG (1996) Topographically specific effects of ELF-1 on retinal axon guidance in vitro and retinal axon mapping in vivo. Cell 86:755-766.

Ohta K, Iwamasa H, Drescher U, Terasaki H, Tanaka H (1997) The inhibitory effect on neurite outgrowth of motoneurons exerted by the ligands ELF-1 and RAGS. Mech Dev 64:127-135.

Simpson IA, Sonne O (1982) A simple, rapid and sensitive method for measuring protein concentration in subcellular membrane fractions prepared by sucrose density ultracentrifugation. Anal Biochem 119:424-427.

Walter J, Kern-Veits B, Huf J, Bonhoeffer F (1987) Recognition of positionspecific properties of tectal cell membranes by retinal axons in vitro. Development 101:685-696.

Wang H, Chadaram SR, Norton AS, Lewis R, Boyum J, Trumble W, Sanes JR, Laskowski MB (1999) Positionally selective growth of embryonic spinal cord neurites on muscle membranes. J Neurosci 19:4984-4993.

Wang H, Chadaram SR, Norton AS, Laskowski MB (2001) Development of inhibition by ephrin-A5 on outgrowth of embryonic spinal motor neurites. J Neurobiol 47:233-243.

Wigston DJ, Sanes JR (1985) Selective reinnervation of rat intercostal muscles transplanted from different segmental levels to a common site. J Neurosci 5:1208-1221.

Wilkinson DG (2001) Multiple roles of EPH receptors and ephrins in neural development. Nat Rev Neurosci 2:155-164.

Xie H, Ziskind-Conhaim L (1995) Blocking $\mathrm{Ca}^{2+}$-dependent synaptic release delays motoneuron differentiation in the rat spinal cord. J Neurosci 15:5900-5911.

Yue Y, Su J, Cerretti DP, Fox GM, Jing S, Zhou R (1999) Selective inhibition of spinal cord neurite outgrowth and cell survival by the Eph family ligand ephrin-A5. J Neurosci 19:10026-10035. 